\title{
Theoretical and practical considerations in the therapy of morpho-functional disorders of the dento-maxillary system in preschool age - preliminary study
}

Irina Adriana BEURAN ${ }^{1}$, Augustin $\mathrm{MIHAl}^{1}$, Viorel Stefan PERIEANU ${ }^{1}$, lleana IONESCU ${ }^{1}$, Oana EFTENE ${ }^{1}$, Simion Gh. DUMITRU ${ }^{2}$, Claudia-Camelia BURCEA ${ }^{1}$, Iuliana BABIUC ${ }^{1}$, Corina Marilena CRISTACHE ${ }^{1}$, Mihai BURLIBASA ${ }^{1}$, Liliana BURLIBASA ${ }^{3}$, Cosmin MEDAR ${ }^{1}$, Maria Glencora COSTACHE ${ }^{1}$, Madalina Violeta PERIEANU ${ }^{1}$, Gabriela TANASE ${ }^{1}$, Oana-Cella ANDREI ${ }^{1}$, 1"Carol Davila" University of Medicine and Pharmacy, Bucharest, Romania ${ }^{2}$ Dental Practice, Brasov, Romania ${ }^{3}$ Faculty of Biology, University of Bucharest, Romania

ABSTRACT
The development of the dento-maxillary system from the very beginning to the age of 12 implies a
multitude of changes in the structure of this system. In the age of growth a sequence of deviations from the
morphology and function of the dento-maxillary system appear.
Purpose. In this paper, we have approached certain aspects of both theoretical and practical aspects that
may intervene in the formation and development of dento-maxillary system in preschool age (up to 6 years).
Material and methods. 75 dental practitioners from of different specialities from Bucharest were
involved in this study between April 15 and May 20, 2018. To carry out a relevant survey a 6 items
questionaire was used.
Result and discussions. The results obtained were structured for a better understanding and to have a
clear view for further study directions.
Conlcusions. The dentist have the most important role in detecting disturbances that may have a negative
effect on formation and development of dento-maxillary system and also is the one who guide prophylactic
actions of preschool age children to avoid negative effect on dento-maxillary system.

Keywords: morpho-functional disorders, preschool age, dentist, age of growths

\section{INTRODUCTION}

During the growth period of humans, a series of more or less severe deviations from the morphology and function of the dento-maxillary system may occur: they very accurately reflect the factors that alter, influence or condition the formation of the dento-maxillary system (1-8).

The 4 main stages that interfere in the growth rate of an individual, are (1-8): 
- Age immediately after birth (first period);

- Preschool age (up to 6 years) (second period);

- The age of 6-12 years, which represents the stage of changing temporary dentition with permanent dentition (third period);

- Age after 12 years (which is the fourth period).

In this context, classical dental care becomes an assistance to prevent and treat morpho-functional disorders between the dento-maxillary constituents that appear throughout life (1-4, 6, 9-13). Generally, all these changes can be detected in real-time with the help of very comprehensive medical imaging exams. Specifically, in this paper, we deal strictly with issues related to preschool age (up to 6 years), which is the second classical stage, which intervenes in the growth rate of an individual.

\section{PURPOSE}

As it is known, the second most important period in the development of dento-maxillary system is preschool age, up to 6 years, the age of temporary dentition, dominated by functional and nutritional factors $(1-4,14)$.

Guiding relationship between maxilla and mandible and their growth and development mode due to the functional factors will be the primary factor, important in the way of implantation of the teeth, but also the primordial development of the periodontium (1-4, 15).

Bad food habits imprinted to children by parents and / or other people directly involved in their education, along with hereditary transmissions of tissue structures deficiencies, determine the functional conditions unfavorable to mastication and the harmonious development of the dento-maxillary system (1-4, 13-18). Thus, the study of these problems is the very purpose of this material.

However, in order to better understand these important aspects in the formation and development of the dento-maxillary system during the preschool period, in the following, there is a need for a concise explanation of the notions defining this particularly important stage of the growth rate of the individuals of our society, aspects that need to be generally known by all dental practitioners, regardless of their specialty and which are the purpose of this report (1-4).

\section{MATERIAL AND METHODS}

During the pre-school age, the role of masticatory activity is particularly important, so (1-4):
- Ensures the development of jaws (the appearance of diastema), a sign that permanent teeth will take place on dental arches;

- Act on relationship between temporary teeth, favoring through their abrasion the second mesial movement of mandible;

- In this age period, food and mastication habits, or rather the stereotype of feeding, which the individual keeps for a long time during his lifetime, are settled.

Also in this period of preschool age, in addition to a series of habits that favor abnormal development, there is also a non-physiological function of the dento-maxillary system. Thus, the tendency of "laziness in mastication" of the preschool age individuals, maintained by their highly dispersed attention which is not conducive to a sustained masticatory effect, adds the habits of adults to nourish children with food that does not require an masticatory special effort (soups, sauces, mashed vegetables, choppers), generally a soft and ultra-soft diet (1-4). Thus, the effects of this poor mastication with which the child may get used to this age are unfavorable (1-4):

- Either directly, for the growth of the jaw bones, which develops as a result of the masticatory muscular activity;

- Or indirectly, on dento-maxillary system activity until the end of life, by setting these food habits and masticatory stereotypes.

Thus, education issue has a prophylactic role, especially useful for future generations, in terms of diet and its content. This counseling should be preferably provided by qualified dental staff.

The influence of the health condition of the tissues through the masticatory act is realized at this age, through the self-maintenance function. Deficient mastication and some abnormal relationship between teeth lead to a poor self-cleaning so that the preschool age children can not avoid dental microbial plaque deposits in the retention areas of the oral cavity, a strong microbial biofilm involved in the tooth decay and periodontal disease genesis (1-4). This insufficient self-cleaning and irrigation of tissues also contributes the reduction of the mobility of the perioral muscles in speech, mimics, the ingestion of food etc. (1-4). But, until the age of 6 , the hygiene of oral cavity is extremely important both from the point of view of direct effects, and especially of indirect effects, by setting habits. It's hard at this age to teach the child the brushing technique, but it's easy to set the brushing reflex at a certain time of the day (morning and evening after eating it) (1-4, 6, 10-18).

In the development of dento-maxillary system, in this period of preschool age, masticatory func- 
tion is also important, with a role in the harmonious development of the face bones. At the same time, the setting of some parafunctional habits, and some pathological reflexes (finger and/or hand sucking, lip biting, infantile swallowing, pencil gnawing) negatively influences the formation and development of dento-maxillary system in this period of preschool age (1-4). In these cases, the role of the dentist is to detect, seize, correct and treat these issues that may occur during preschool age, in the formation and development of dento-maxillary system (1-4).

Regarding the odontal pathology, it can be noticed that at preschool age, the presence of caries in temporary dentition have an important dysfunctional role in the disorders of the dentomaxillary system (1-4). Thus, a last aspect that we will discuss in this paper is that the caries treatment of temporary dentition is mandatory (1-4). This must lead biologically to healing and, morphologically, to the restoration of the functional form that ensures the quality and correctness of the treatment, because it can not be minimized the role of restoring morphology in assuring the relationship between the teeth of the two growing dental arches (1-4, 8-14).

To carry out a relevant survey, we compiled a questionnaire of 6 items applied to 75 dental practitioners (simple dentists, resident doctors, specialists and high specialists in dental medicine specialties: general dentistry, dental prosthodontics, orthodontics and dentofacial orthopedics, pedodontics, endodontics, dento-alveolar surgery, periodontics, maxillo-facial surgery). Subjects were aged between 31 and 70 and had the fol- lowing sex distribution: 55 of the subjects were female $(73.33 \%)$, while the remaining 20 subjects were male (26.67\%) (Fig. 1). The study was conducted between April 15 and May 20, 2018.

The questionnaire applied to the 75 subjects is as follows:

\section{Questionnaire}

1. How do you assess the role of masticatory activity in the formation and development of dento-maxillary system during preschool age? a. Very important; b. Average importance. C. No significant importance?

\section{Correct answer: $\boldsymbol{a}$.}

2. How do you assess the masticatory effort should be in the case of preschool age individuals?

a. Sustained masticatory effort resulting from a diet that predominates roasted meat, crumbs, bread crust, and other foods that require a certain masticatory effort, and also favorably affects the self-cleaning function;

b. Light masticatory effort, based on a liquid and fine ground diet, consisting of soups, broths, mashed vegetables, sauces, etc.;

c. Disrespecting the rhythmicity of the meals and the breaks between them, the habit of adults to give children sweets between the meals, influences this masticatory effort;

d. Providing pre-school age children with a high-calories diet above the required level, mainly composed with hydrocarbons, to the detriment of proteins, minerals and enzymes, affects the masticatory effort.

Correct answer: $a$.

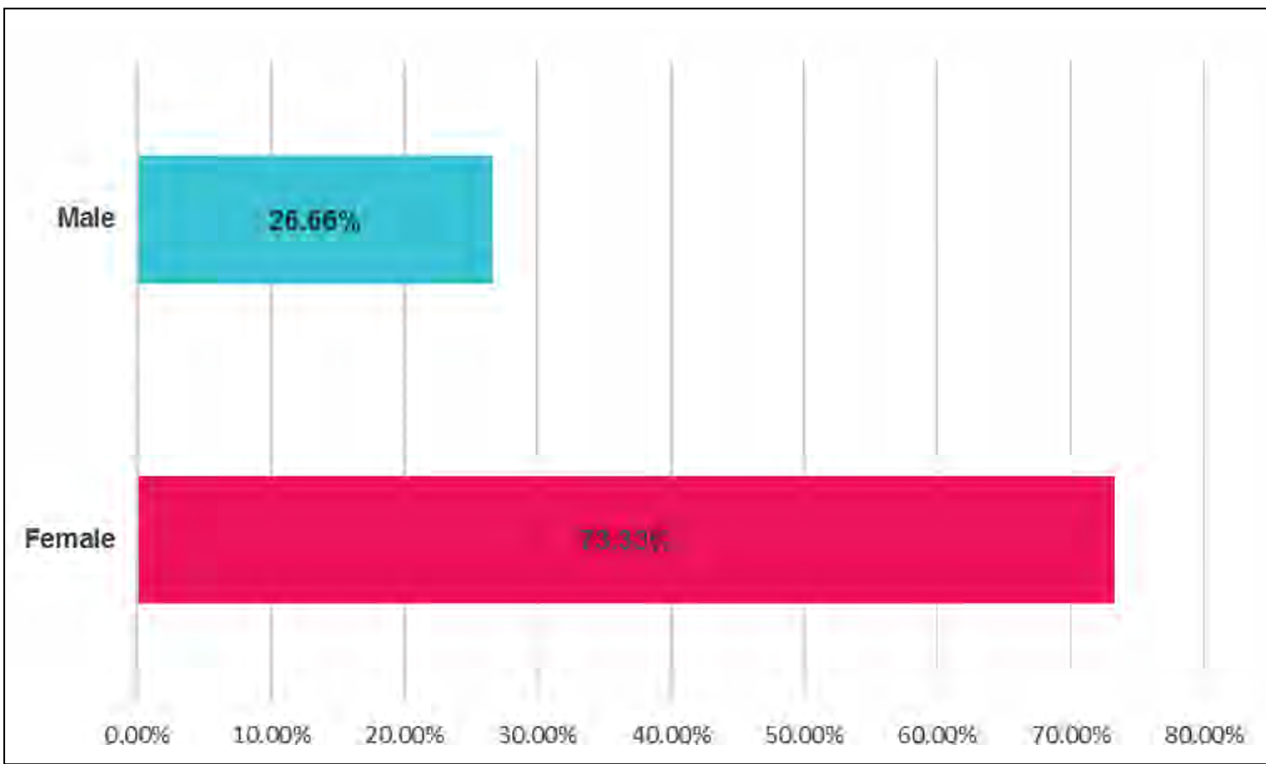

FIGURE 1. Gender distribution of the subjects involved in the study 
3. Problem of proper nutrition, in terms of masticatory effort:

a. Requires prophylactic education, ensured by highly qualified dental staff?

b. Requires prophylactic education, strictly assured by pediatricians and nutritionists?

c. Does it require education and advice in any way?

\section{Correct answer: $a$.}

4. The self-maintenance function, supplemented by good oral hygiene for preschool children (up to 6 years of age), is maintained by?

a. Proper, dynamic mastication, good selfcleansing, proper irrigation of tissues, supplemented with a child's reflexive teeth brushing at a specific moment of the day (morning and evening after eating);

b. Deficient mastication, insufficient self-cleaning and irrigation of tissues, and lack of teeth brushing;

c. Is it irrelevant.

Correct answer: $a$.

5. How do you assess the role of the dentist in detecting respiratory disorders, parafunctions, and pathological reflexes (finger and/or hand sucking, lip biting, infantile swallowing, pencil gnawing) with negative impact on the formation and development of the dento-maxillary system:

a. Very important.

b. Average importance.

c. No importance?

Correct answer: $a$.

6. Tooth decay treatment at preschool age (in temporary dentition) is?

a. Mandatory;

b. It must lead biologically to healing; c. It must lead morphologically to the restoration of the functional form;

d. It does not make sense to be realized, considering that we are talking about temporary dentition?

Correct answers: $a, b, c$.

\section{RESULTS AND DISCUSSIONS}

The results obtained from the analysis of the questionnaire applied to the 75 practitioners are synthesized and plotted as follows:

The role of masticatory activity in the formation and development of the dento-maxillary system, although seen differently by practitioners remains an important factor for most of them (63 - representing $84 \%$ ), while a small number of doctors consider it of medium importance (8 practitioners $-10.67 \%$ ) or unimportant (4 practitioners $-5.33 \%$ ) (FIG. 2).

With regard to the masticatory effort, all practitioners considered that it must be a sustained one, based on foods that require the masticatory muscles and at the same time favorably affects the self-cleaning function.

Regarding the education of pre-school children for a proper diet in terms of masticatory effort, most doctors consider it should be done by qualified dental staff (69 doctors -92\%) while only 6 doctors ( $8 \%$ ) believes that this should be done by pediatric or nutritionist specialists (FIG. 3).

All participants in the study agreed that the self-maintenance function is achieved through a correct and dynamic mastication accompanied by a proper brushing in the morning and evening.

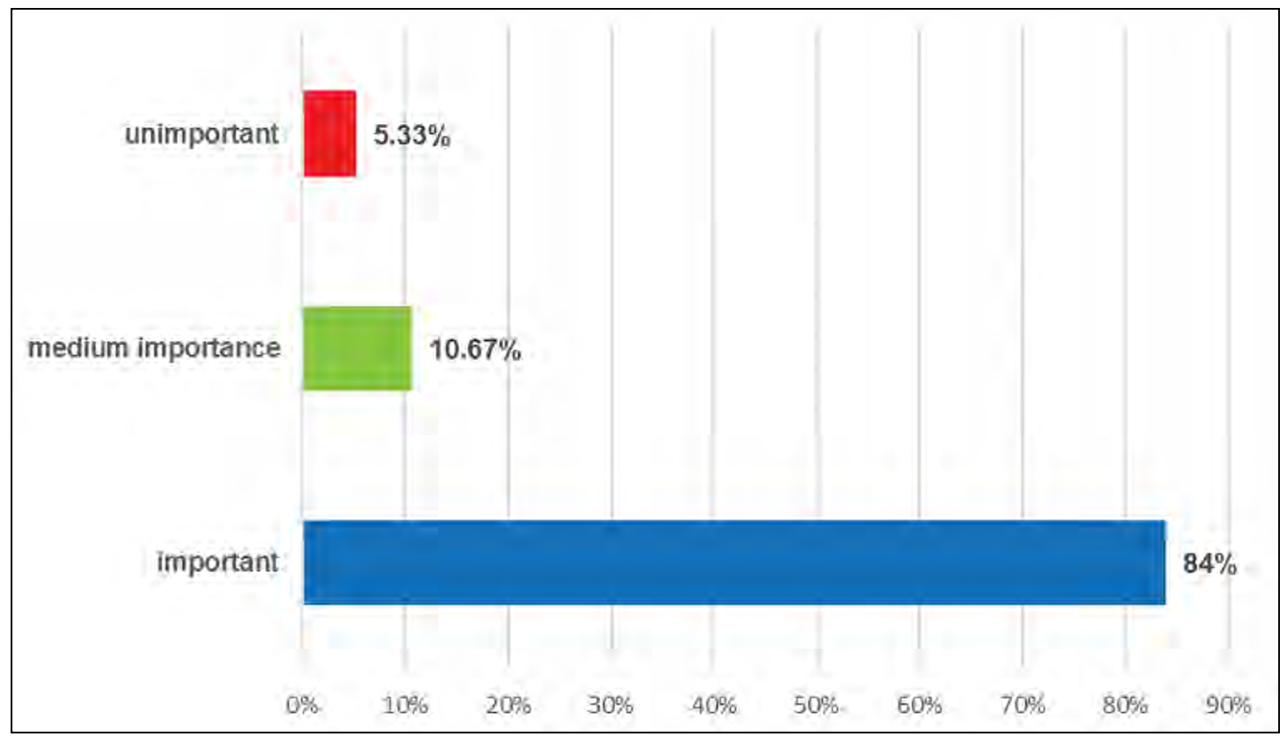

FIGURE 2. The role of masticatory activity 


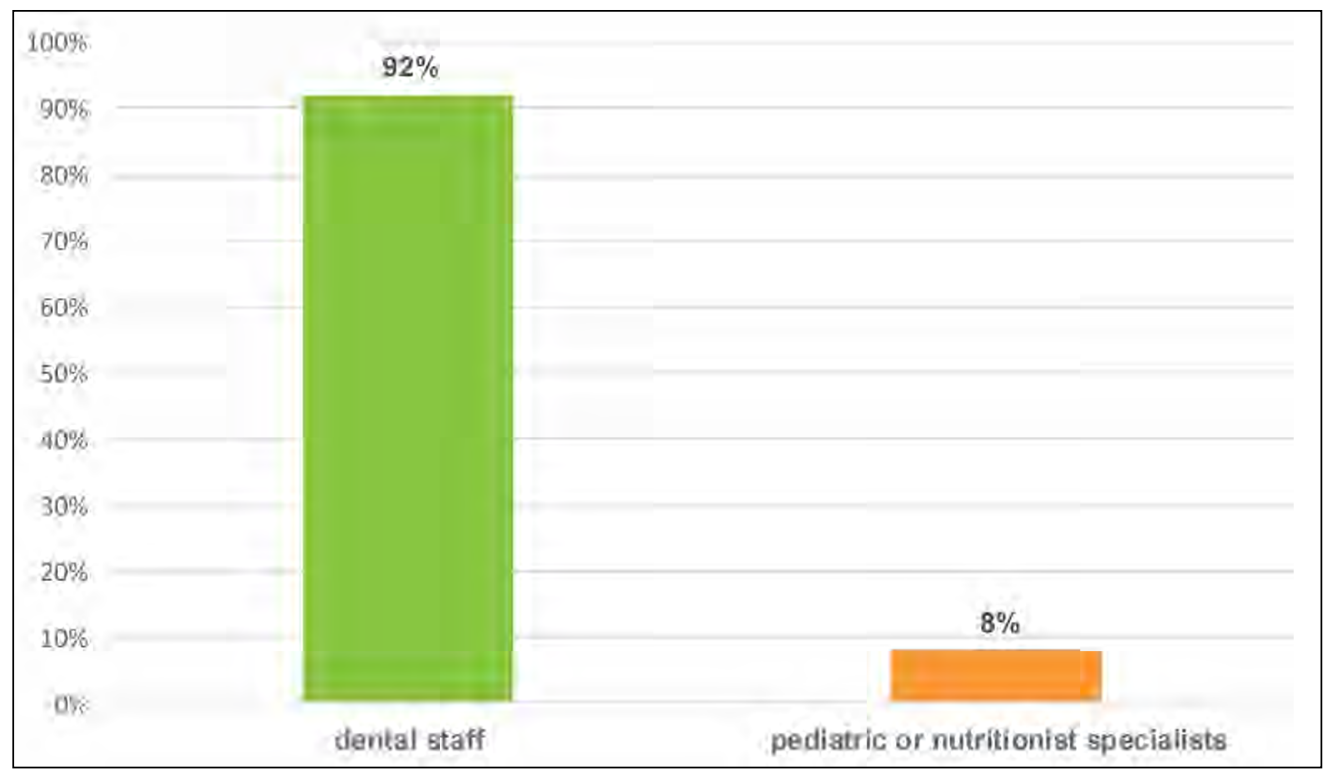

FIGURE 3. Achieving education for proper nutrition

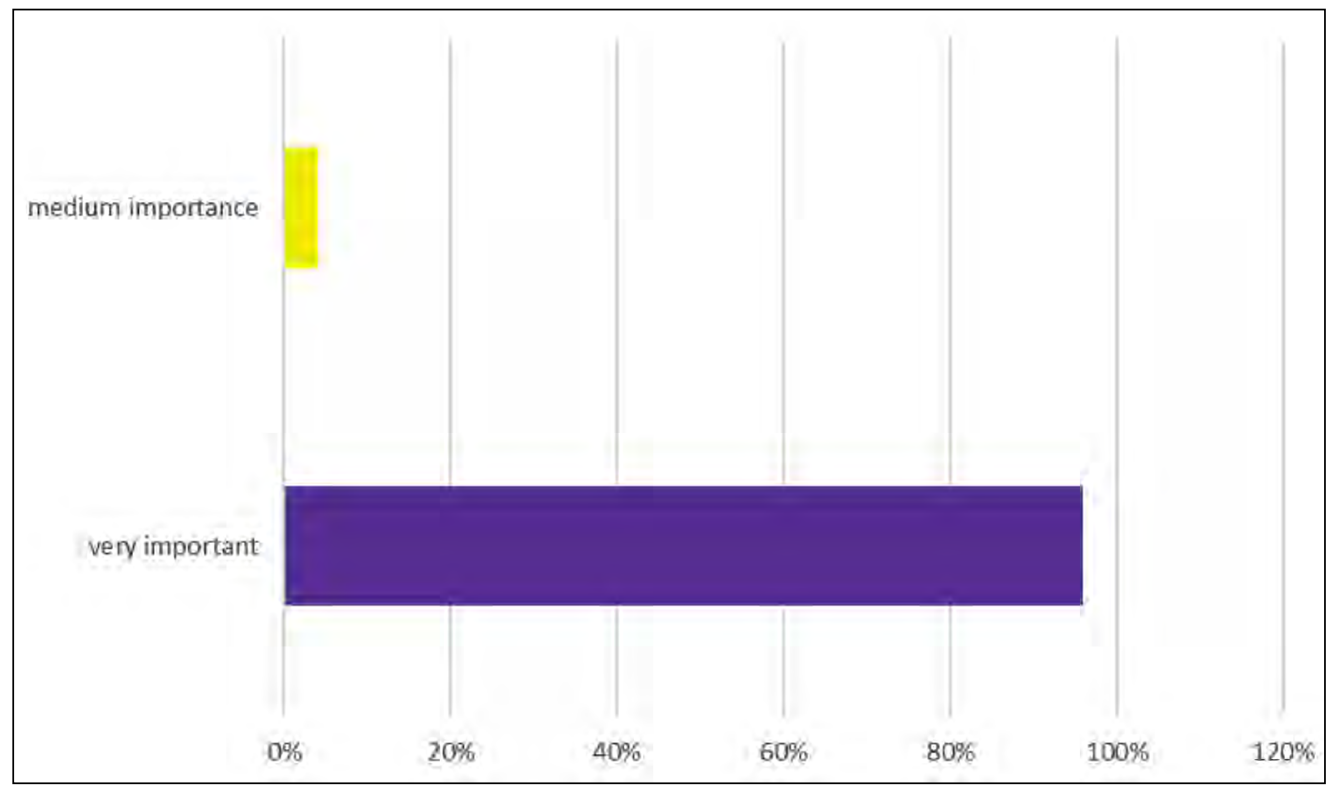

FIGURE 4. The dentist's role in detecting disorders that may affect the dento-maxillary system

Regarding the role of the dentist in detecting disorders that may have a negative impact on the formation and development of the dentomaxillary system, 72 of the subjects (representing $96 \%)$ consider it very important, whereas only 3 subjects (representing 4\%) considers it of medium importance (FIG. 4).

In the last question on tooth caries treatment of preschool age individuals, all participants in the study offered the right answers, respectively, to lead to healing and the restoration of the functional form.

\section{CONCLUSIONS}

Following the evaluation of the answers to the six questions, we can conclude on several aspects, some of which are extremely important, as follows:

1. Although it is impossible to influence today's adult eating habits, through well sustained education methods of qualified dental staff, it could be influenced the education of the preschool children that could become accustomed to a diet in which predominates roasted meat, crumbs, bread crust, 
and other foods that require a certain masticatory effort and have a positive influence on the selfcleaning function.

2. Deficient mastication and reduction of oral and perioral muscular activity diminishes selfcleansing, which requires active intervention to supplement it by good oral hygiene.

3. The role of the dentist in detecting respiratory disturbances, parafunctions, pathological reflexes (finger and/or hand sucking, lip biting, infantile swallowing, pencil gnawing) with negative impact on the formation and development of dento-maxillary system is of the utmost importance, and it has the essential role of detecting, sensing, correcting and treating these issues that may occur during preschool age. Follow-up of how these complex activities are carried out at the level of dento-maxillary system and the intervention, for the correction by gymnastics of the perioral muscles, by guiding the masticatory activity, the function of swallowing, phonation, diction, respiration, as well as removing vicious habits, are the most important means of prophy- laxis at this age. Prophylactic actions are very effective at preschool age, bearing in mind both the child's modeling character and the importance of the moment in the formation and development of dento-maxillary system. Generally, after the age of 6 , the dentist's effort to correct the above-mentioned situations, which will be the consequence of these poor functions and paraphunctions, will be much more difficult.

4. In the curative therapy of dental injuries during preschool age (temporary dentition), consideration should be given to the important role in the formation and development of the dentomaxillary system, the tooth shape reproduction and rendering real dental arches relationship. The execution of therapeutic acts should be done with the same care and rigor, as with permanent dentition.

\section{Acknowledgement}

In this article, all the authors have equal contributions with the first author.

\section{Conflict of interest: none declared Financial support: none declared}

\section{REFERENCES}

1. Miyasaki-Ching CM. Elemente clinice de stomatologie. Editura All Educational, București, 2001.

2. Gall II. Ásistența stomatologică. Editura Didactică și Pedagogică, București, 1971.

3. Rosenstiel SF, Land MF, Fujimoto J. Contemporary fixed prosthodontics. Fourth Edition. Mosby Elesvier, 2006.

4. Anusavice K. Phillip's science of dental materials. 11th edn. Philadelphia: WB Saunders, 2003.

5. Gavrila L, Mircea L. Chromatin and chromosomal fine structure in spermatogenesis of some species of amphibians. Zygote. 2001; 9(3), 183-192.

6. Cristache CM, Burlibașa M, Cristache $\mathrm{G}$ et al. Zirconia and its biomedical applications. Metalurgia International. 2011; 16(7), 18, p. 18-23.

7. Burlibașa M, Cernușcă-Mițariu M, Burcea $\mathrm{CC}$ et al. Halogen compounds - theoretical, physiological and practical aspects regarding the decontamination, disinfection and sterilisation of intsruments and biomaterials in dental medicine practice. Metalurgia International. 2013; Vol. XVIII, Spec. Issue No. 3, p. 54-57.

8. Tănase $G$, Burlibașa M, Muntianu L et al. Testing the antibacterial potential of biomaterials in medical practice. Metalurgia International. 2009; Vol. XV, Spec. Issue No. 2, p. 160-162.

9. Burlibașa M, Muntianu L, Tănase $G$ et al. Study on microbial contamination of biomaterials in medical practice. Metalurgia International. 2009; Vol. XV, Spec. Issue No. 2, p. 163-166.

10. Popescu FD, Popescu SM, Burlibașa M. Platinum group metals a contact allergens in oral rehabilitation. Metalurgia International. 2009, Vol. XV, Spec. Issue No. 3, p. 12-18.

11. Cristache $\mathrm{CM}$, lonescu $\mathrm{C}$, Cristache $\mathrm{G}$ et al. A 5-year prospective randomised clinical trial on the efficiency of two different attachment systems as retention for implant-supported mandibular overdenture. Radiographic assessment, cost analysis and final evaluation of treatment's success. Metalurgia International. 2008; Vol. XIV, Spec. Issue No. 16, p. 27-34.

12. Burlibașa $M$, Cuculescu $M$, Tănase $G$ et al. Dental alloys of prothetic use - a retrospective of their use in Romania. Metalurgia International. 2008; Vol. XIV, Spec. Issue No. 16, p. 51-53.

13. Cristache $\mathrm{CM}$, Ionescu $\mathrm{C}$, Burlibașa $\mathrm{M}$ et al. Rettentive anchors versus magnets as attachment systems for mandibular overdenture. A 5 year prospective randomised clinical study. Metalurgia International. 2009; Vol. XIV, Spec. Issue No. 16, p. $59-64$.

14. Burlibașa $L$, Zarnescu $O$. In vivo effects of Trichostatin A-A histone deacetylase inhibitor - on chromatin remodeling during Triturus cristatus spermatogenesis. Animal reproduction science. 2013; 142 (1-2), 89-99.

15. Burlibașa L, Gavrila L. Developmental epigenetics: Roles in embryonic development, in Nutrition in Epigenetics (eds. Niculescu MD, Haggarty P.); 2011, Ch. 6, p. 105-126, Willey-Blackwell Publishing.

16. Ștețiu AA, Oleksik M, Oleksik V et al. Mechanical behavior of composite materials for dental obturations. Romanian Biotechnological Letters. 2013; 18(4), p. 8528-8538.

17. Mocuța D, Popovici LR, Dumitriu AS et al. Life quality-condition of social welfare. Metalurgia International 14, 2009, 62-64.

18. Burlibașa M, Burlibașa L, Gavrilă LB et al. microRNA a macro Revolution in Medical Biotechnologies. Romanian Biotechnological Letters 13(6), 2008, 3977-3983. 